\title{
Telomerase activity in human leukemic cells with or without monosomy 7 or 7q- Nedime Serakinci ${ }^{1}$ and Jørn E Koch*2
}

Address: ${ }^{1}$ Present Address: Institute of Human Genetics, University of Aarhus, DK-8000 Aarhus C, Denmark and ${ }^{2}$ Institute of Pathology, Aarhus Kommunehospital, Nørrebrogade 44, DK-8000 Aarhus C, Denmark

E-mail: Nedime Serakinci - nedi@humgen.au.dk; Jørn E Koch* - jokoc@akh.aaa.dk

${ }^{*}$ Corresponding author

Published: 29 October 2002

BMC Medical Genetics 2002, 3:I I

This article is available from: http://www.biomedcentral.com/I47I-2350/3/II

(C) 2002 Serakinci and Koch; licensee BioMed Central Ltd. This article is published in Open Access: verbatim copying and redistribution of this article are permitted in all media for any purpose, provided this notice is preserved along with the article's original URL.
Received: 10 July 2002

Accepted: 29 October 2002

\begin{abstract}
Background: In bone marrow material from patients with various leukemias we noted that samples with either a deletion on the long arm of one chromosome 7 (7q-) or a monosomy 7 had a higher telomerase activity. Considering that introduction of a chromosome 7 into a cancer cell line had been reported to eliminate telomerase activity, that $7 q$ - is a common negative prognostic finding in cancers, and that the deleted segment (band 7q3I) contains an unidentified tumor suppressor gene, we wondered if this gene might be a telomerase inhibitor.
\end{abstract}

Results: We found no significant difference in telomerase activity between the three groups of patient samples. In contrast to reports on tumor cell lines we observed no amplification of the telomerase genes.

Methods: We analyzed telomerase activity and copy number of the telomerase genes hTERT and hTR in frozen archival bone marrow samples from leukemia patients with a referral diagnosis of AML, and either a monosomy for chromosome 7, a deletion on the long arm of chromosome 7 (7q-), or none of these aberrations. Telomerase activity was measured with a commercially available kit, and the copy number of the telomerase genes was tested by FISH.

Conclusions: We found no evidence of a telomerase inhibitor in band $7 q 31$. The lack of telomerase gene amplification found in cell lines from solid tumors could reflect that this amplification is a property of solid tumors, not of hematological cancers.

\section{Background}

Somatic cells have a limited potential for cell division, in part due to an absence of telomerase activity in such cells [1]. Cancer cells grow indefinitely, either depending on telomerase activity or an alternative mechanism for telomere elongation (ALT) [2,3]. It has long been suspected that the absence of telomerase activity, and the resulting limited potential for cell division, acts as an anti-oncogenic mechanism in normal somatic cells. In line with this view, recent reports demonstrated that telomerase activation was among the genetic changes needed to transform normal cells in vitro[4], and that telomerase inhibition caused growth arrest and cell death in cancer cell cultures [5]. In cancer cells, telomerase activation has been described, as well as up-regulation of preexisting telomerase activity. However, the mechanisms for regulating of telomerase activity described so far all have a quantitative ef- 
$1 \mathrm{~A}$.

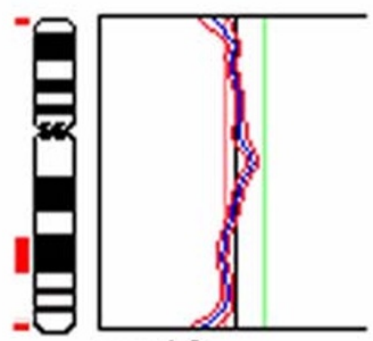

$n=16$

7
$1 \mathrm{~B}$

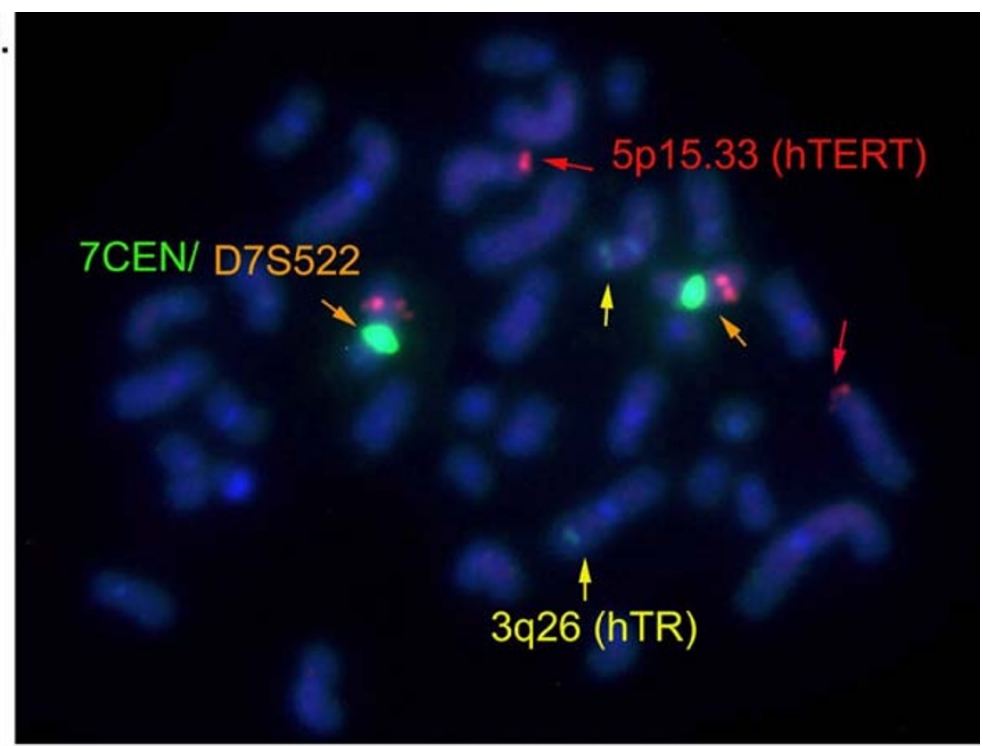

1D.

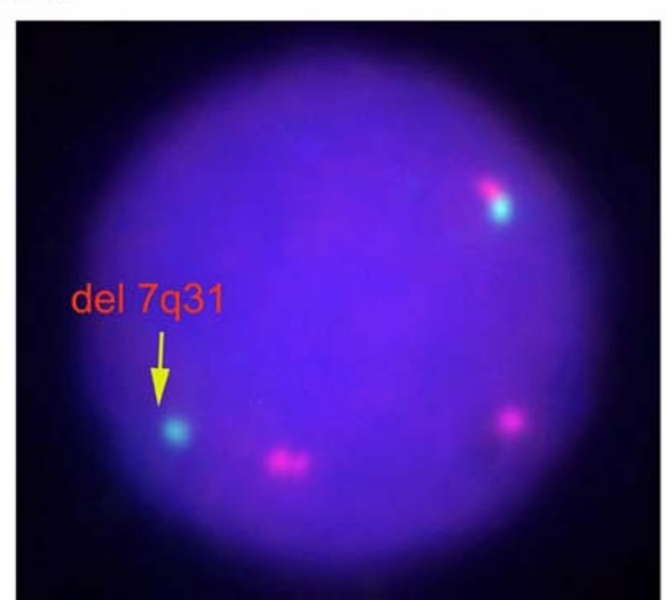

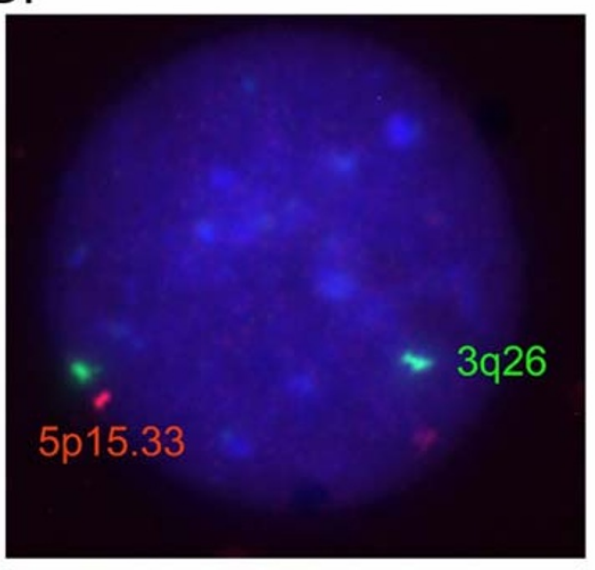

Figure I

$\mathrm{CGH}$ analysis of chromosome 7 in the 7q- samples and FISH analysis of the relevant regions on chromosomes 3, 5 and 7. A. $\mathrm{CGH}$ analysis of pooled DNA from the 7q- samples hybridized against control DNA from a normal male donor. The CGH profile for chromosome 7 is shown. A deletion is seen in the $7 \mathrm{q} 3 \mathrm{I}$ region as indicated on the idiogram. B. Triple color hybridization for 7CEN/D7S522, hTERT, and hTR. 7CEN (orange arrows) and hTR (yellow arrows) appear in green. In the microscope the hTR signal was bright and clearly visible, but in the present representation it appears weak due to the auto exposure in the green channel being governed by the stronger 7CEN signal (compare with panel D). Both D7S522 (orange arrows) and hTERT (red arrows) appear red in this representation. In the microscope, each of the two probes appeared in its recognizable reddish color, but the difference could not be reproduced here. C. Dual color hybridization of hTERT (red) and chromosome 7 probes (green centromere juxtapositioned with red 7S522). While both hTERT loci are labeled, one chromosome 7 has only a centromere signal, and not a 7q3I signal. D. Dual color hybridization of the hTR and hTERT probes showing two signals for each probe. This was the general finding in all 65 samples. In the absence of the green centromere 7 signal the hTR probe is clearly visible after auto exposure.

fect on the enzyme, whereas no switch closing telomerase down has been discovered [6].

Analyzing bone marrow samples from leukaemia patients in another study, we made the observation that samples with either a deletion on the long arm of one chromo- some 7 (7q-) or a full monosomy 7 displayed a significantly higher average telomerase activity compared to samples without these abnormalities (unpublished results). This chance observation made us wonder if chromosome 7 might harbor a telomerase suppressor, the loss of which would cause increased telomerase activity in cas- 


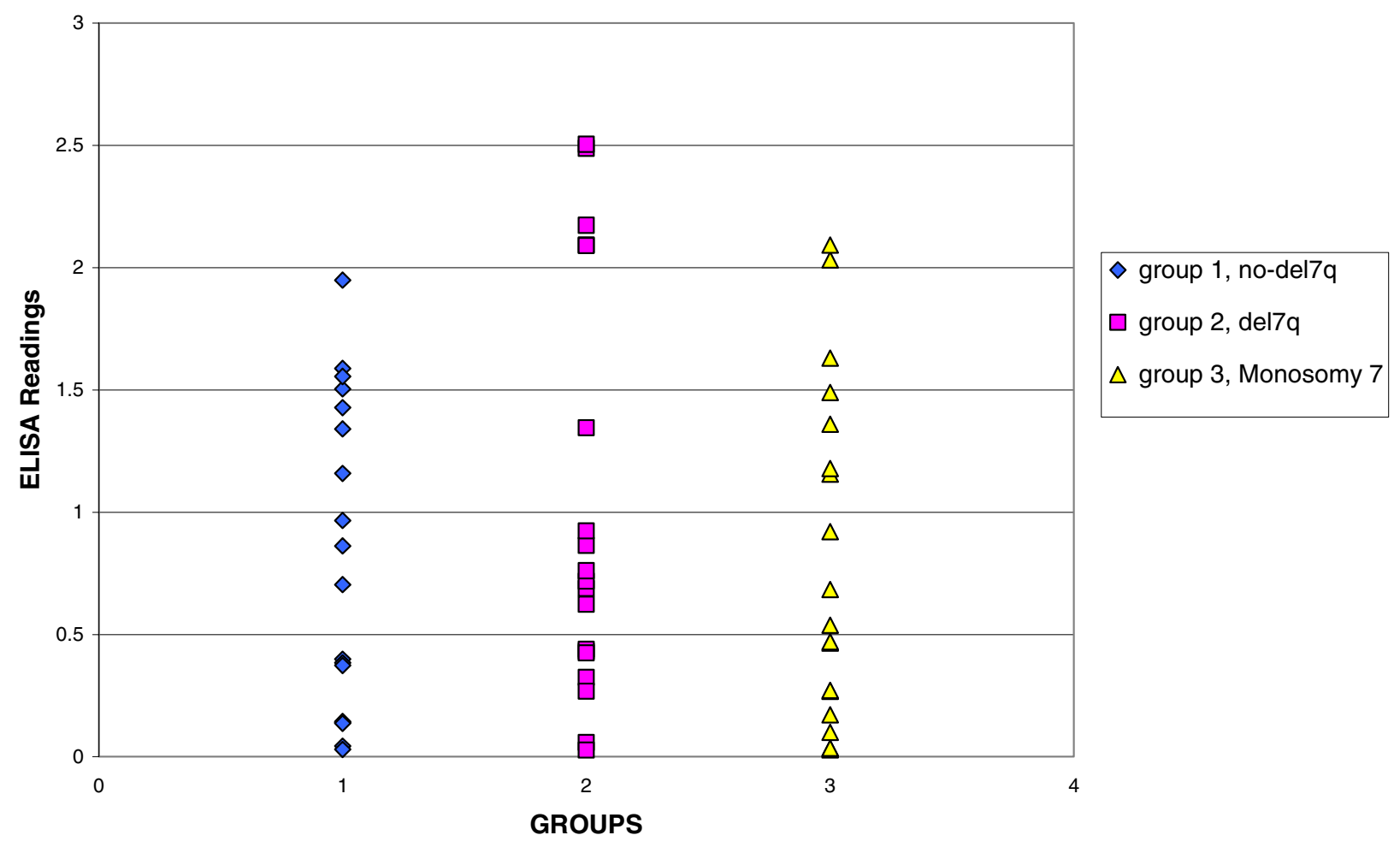

Figure 2

ELISA readings for telomerase activity in the three categories of patient samples.

es with -7 or $7 \mathrm{q}-$. Looking into the literature we found that introduction of a chromosome 7 into a telomerase positive cancer cell line eliminates the telomerase activity [7], that $7 \mathrm{q}$ - is a common finding in many cancers $[8,9]$ with an invariably ominous prognosis, and that the commonly deleted segment (band 7q31) contains a yet unidentified tumor suppressor gene [10]. Based on these reports we formed the hypothesis that the unknown tumor suppressor in 7q31 might in fact be a telomerase inhibitor, perhaps an on/off switch for telomerase activity.

Another factor that might potentially affect telomerase activity is amplification of the telomerase genes. Such amplification has been reported for a number of solid tumors and cancer cell lines $[11,12]$, and could be speculated to overwhelm even otherwise intact telomerase inhibition. For the study reported here we therefore combined analysis with FISH probes and measurements of telomerase activity on all archival frozen bone marrow samples we had available from patients with a registration as AML and cytogenetic finding of either -7 or $7 q-$. Samples without a recognized chromosome 7 abnormality were analyzed as control. For the FISH part of the study, probes for $7 \mathrm{q} 31$ were combined with probes for the two telomerase genes, hTERT and hTR $[12,13]$.

We found no amplification of either hTR or hTERT in any of the tumor categories, and while FISH and CGH could confirm the 7q31 deletions identified by G-banding, the average telomerase activity did not differ significantly between the tumors. This result leads to two conclusions. One is that since we found no effect on telomerase activity of chromosome 7 aberrations in this larger patient material, we find no evidence of a telomerase suppressor gene in $7 q 31$. The other conclusion is that since we found no evidence of amplification of telomerase genes in AML, upregulation of telomerase activity in this type of cancer might be different from up-regulation of telomerase activity in solid tumors.

\section{Methods}

\section{Patient material selection}

G-banding results were retrieved from the files of the department. These data had originally been obtained in the course of routine diagnosis. Samples with a registration as AML and a cytogenetic diagnosis of -7 or $7 q-$ by G-band- 


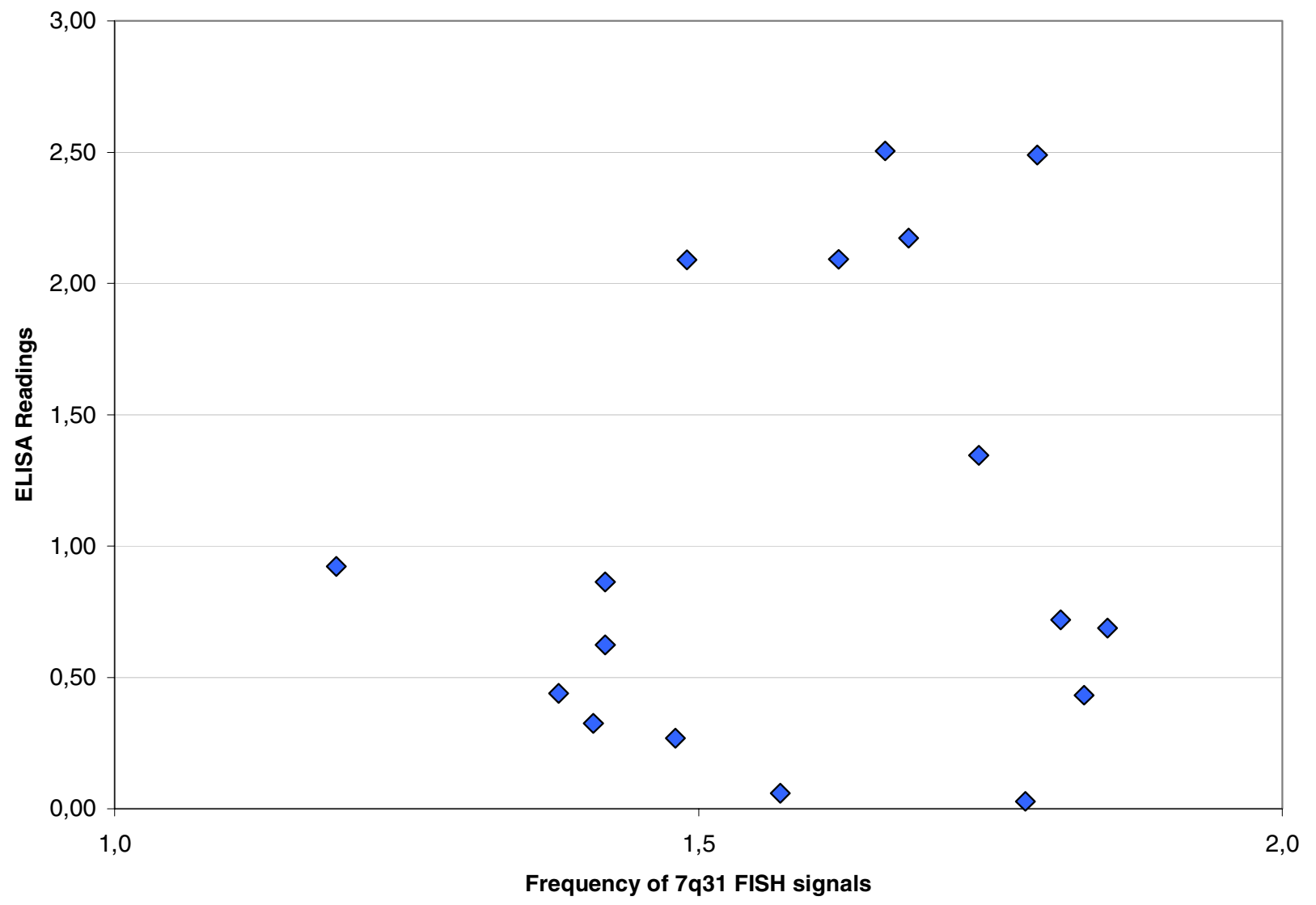

Figure 3

Correlation between ELISA readings for telomerase activity and the frequency of $7 q 31$ FISH signals in individual samples from the $7 q-$ patients.

ing were selected. Samples in which frozen cells were also available for telomerase activity determination were included in the study. This gave us about 20 samples in each of the two categories, so we added an additional $20 \mathrm{AML}$ cases without any of the abnormalities for control purposes. In all three groups of patients some of the cases selected eventually had to be left out for technical reasons, such an insufficient amount of material, so the actual numbers of samples studied became 17, 17, and 19, respectively. There was no significant difference in age or sex distribution between the patient groups with $-7,7 \mathrm{q}$ - or no aberration on chromosome 7 . There was also no overall difference in the karyotype complexity between the test and the control groups, beyond the presence or absence of chromosome 7 aberrations.

\section{Probes for FISH and CGH}

Chromosome 7CEN/D7S522 and 7CEN7D7S486 probes were commercially available (Vysis, Inc. Downers Grove, IL 60515, USA, AH diagnostics, Denmark). They include a centromere 7 probe labeled with Spectrum Green and a locus specific probe in $7 \mathrm{q} 31$ labeled with Spectrum Orange. FISH hybridization and post-hybridization washes were performed as specified by the manufacturer.

The probe for the reverse transcriptase component of telomerase (hTERT, band 5p15.33) was a BAC clone, and the probe for the RNA template component (hTR gene, band $3 \mathrm{q} 26)$ was a P1 clone. Both were kindly provided by Nicole Keith (Glasgow, UK $[12,13]$ ). They were labeled by standard nick translation. 
Table I: Results of triple color FISH reactions with probes for $7 q 3 \mathrm{I}, \mathrm{hTERT}$ and $\mathrm{hTR}$ given as the average number of signals per cell in each sample tested.

\begin{tabular}{|c|c|c|c|c|c|c|c|}
\hline 3q (hTERC) & 3q (hTERC) & 5p (hTERT) & 5p (hTERT) & 7q (D7S486) & 7q (D7S486) & 7q (D7S522 & 7q (D7S522) \\
\hline 7q deletion & no 7q delet & 7q deletion & no 7q delet & 7q deletion & no 7q delet & 7q deletion & no 7q delet \\
\hline ।,83 & 1,95 & 1,95 & 1,98 & $I, 4 \mid$ & 1,95 & 1,40 & 1,97 \\
\hline 1,92 & 1,96 & 1,80 & 1,96 & 1,83 & 1,94 & $1,8 \mid$ & 1,95 \\
\hline 1,86 & 1,92 & 1,93 & 1,88 & 1,38 & 1,96 & 1,52 & 1,93 \\
\hline 1,82 & $\mathrm{I}, 88$ & 1,85 & 1,80 & 1,85 & 1,97 & 1,79 & 1,97 \\
\hline 1,96 & 1,94 & 1,84 & 1,97 & $\mathrm{I}, 48$ & 1,96 & 1,42 & 1,96 \\
\hline 1,88 & 1,88 & 1,82 & 1,94 & 1,42 & 1,94 & 1,40 & 1,94 \\
\hline 1,86 & 1,94 & 1,78 & 1,94 & 1,68 & 1,98 & 1,66 & 1,98 \\
\hline 1,94 & 1,93 & 1,90 & 1,94 & 1,62 & 1,95 & $\mathrm{I}, 40$ & 1,95 \\
\hline ।,87 & 1,82 & 1,95 & 1,89 & 1,79 & 2,00 & $\mathrm{I}, 75$ & 2,00 \\
\hline 1,52 & 1,70 & 1,83 & 1,84 & 1,81 & 1,97 & 1,80 & 1,97 \\
\hline 1,89 & 1,95 & 1,91 & 1,99 & 1,19 & 1,96 & $\mathrm{I}, 44$ & 1,96 \\
\hline 1,92 & 1,97 & 1,93 & 2,00 & $\mathrm{I}, 74$ & 1,98 & 1,73 & 1,98 \\
\hline 1,90 & 1,93 & 1,82 & 1,93 & 1,49 & 1,96 & 1,49 & 1,96 \\
\hline$|, 8|$ & 1,95 & 1,90 & $\mathrm{I}, 84$ & $\mathrm{I}, 57$ & 1,91 & I,55 & I,91 \\
\hline 1,85 & 1,85 & 1,85 & 1,97 & 1,78 & 1,97 & I,82 & 1,97 \\
\hline 1,65 & 1,94 & 1,82 & 1,92 & $\mathrm{I}, 42$ & 1,95 & 1,38 & 1,94 \\
\hline I,45 & 1,82 & 1,88 & 1,81 & 1,66 & 1,97 & 1,69 & 1,95 \\
\hline
\end{tabular}

Signal frequencies were generally in the I.8-2.0 range, except that the 7q- samples showed the expected reduction in signal frequency with the $7 \mathrm{q} 3 \mathrm{I}$ probes. For the hTR and hTERT probes the frequencies never exceeded 2.0, nor did we observe signals that were enhanced in intensity. In fact, some samples instead showed deletion of one of the genes in a fraction of cells.

CGH analysis [14] of pooled DNA to determine the common deleted region in the $7 \mathrm{q}$ - group was performed essentially as described previously by Knuutila [15]. In brief, "test" DNA from the patients and reference DNA from a healthy male donor was isolated with Wizard Genomic DNA Purification Kit (Promega) and labeled by standard nick translation. The labels used were fluorescein-12dUTP and tetramehylrhodamine-5-dUTP (Roche), and both pooled patient DNA and reference DNA was labeled in either color, so that green test could by hybridized against red reference and red test against green reference.

\section{FISH and CGH analysis}

When surplus methanol acetic acid (standard Carnoy fixative) fixed cells from the original chromosome analysis were available these were used, otherwise freshly thawed cells were treated with $75 \mathrm{mM} \mathrm{KCl}$ and fixed in Carnoy fixative. Prior to FISH or CGH, slides were "aged" at room temperature for 3-5 days, and denatured in $1 \times$ Tth buffer $\left(10 \mathrm{mM}\right.$ Tris HCL, pH $8.9\left(25^{\circ} \mathrm{C}\right) ; 0.1 \mathrm{~m} \mathrm{KCl} ; 1.5 \mathrm{mM}$ $\mathrm{MgCl}_{2} ; 50 \mathrm{mg} / \mathrm{ml}$ bovine serum albumin; and $0.05 \% \mathrm{v} / \mathrm{v}$ Tween 20 ) at $93^{\circ} \mathrm{C}$ for $2.5 \mathrm{~min}$. Hybridizations were performed as previously described [16].
Images were captured from a standard fluorescence microscope (Lieca DMRB) with a SenSys CCD camera using auto-exposure time and controlled by the "SmartCapture VP" software (Digital Scientific Ltd.). For CGH 10 metaphases from each reaction was analyzed with the Quips software (Vysis). Thresholds for gains and losses were set at 1.20 and 0.80 , respectively.

\section{Assay for telomerase activity}

Telomerase activity was measured with the commercially available ELISA-based kit from Roche, and performed according to the manual included with the kit. To ensure reproducibility and that the values obtained could be compared all samples were analysed at least twice and in different combinations of samples.

\section{Results and Discussion}

In the $7 \mathrm{q}$ - patient material we were able to confirm the presence of a common deleted region in $7 \mathrm{q} 31$ by CGH with pooled patient DNA (Fig 1A). Similarly, FISH with probes D7S486 and D7S522 confirmed that one copy of genes in that chromosome band had been lost in a fraction of cells from all the 7q- patients (Fig 1B,1C and Table 1). The control probes labeled $7 \mathrm{q}$ - and control cells to the same extent (Fig 1B,1C,1D and Table 1), confirming that 
the missing $7 \mathrm{q} 31$ signals were not absent due to an artifact. Surprisingly, no significant difference in telomerase activity was observed between the -7 , the $7 \mathrm{q}-$, and the control samples (Fig 2). Likewise, there was no correlation between telomerase activity and the fraction of cells with 7qin a sample (Fig 3 ). Thus, we found no evidence that the tumor suppressor in band $7 \mathrm{q} 31$ is involved in regulating telomerase activity.

It has been reported that the hTERT gene is amplified in a sizeable fraction of cancers and cancer cell lines [11,12]. The inclusion of FISH probes for hTERT and hTR in this study provided data on the possible similar telomerase gene amplification in AML. None of the 53 samples tested showed such amplification (Fig 1D and Table 1I), arguing strongly against it being a common phenomenon in AML. Hematological cancers differ from most other cancers in that they originate from cells with a low level of natural telomerase activity. Acquiring the necessary telomerase activity for cancer growth in leukemia thus only requires upregulation of telomerase activity, whereas others cancers need to overcome a complete telomerase inhibition, possibly by amplifying telomerase genes to overwhelm telomerase repressors. As an illustration of this difference between hematological cancers and other cancers, the ALT mechanism for telomere elongation is largely confined to the latter group. It is therefore tempting to speculate that telomerase up-regulation in hematological cancers and in solid tumor may develop along different pathways.

\section{Competing interests}

None declared.

\section{Authors' contributions}

NS identified the samples, carried out the experimental work, compiled the data, performed the statistical analysis, produced the illustrations, and participated in the editing of the manuscript. JK conceived of and designed the study, supervised the experimental work and the data compilation, and drafted and edited the manuscript.

\section{Acknowledgements}

NS was employed on a grant to JK from the Danish Medical Research Council. The study was largely performed on equipment obtained on instrumentation grants to JK from The John and Birthe Meyer Foundation.

\section{References}

I. Hayflick L, Moorhead P: The serial cultivation of human diploid cell strains. Exptl Cell Res 196I, 25:585

2. de Lange T: Tumor telomeres. In: Telomeres (Edited by: Blackburn EH, Greider (W) Cold Spring Harbor, Cold Spring Harbor Laboratory Press 1995, 264-293

3. Lundblad V: The end replication problem: More than one solution. Nature Medicine 1997, 3:1 I98-1 I99

4. Hahn WC, Counter CM, Lundberg AS, et al: Creation of human tumor cells with defined genetic elements. Nature 1999, 400:464-468

5. Villa R, Folini M, Lualdi S, et al: Inhibition of telomerase activity by a cell-penetrating peptide nucleic acid construct in human melanoma cells. FEBS Letters 2000, 473:24I-248
6. Shay JW: At the end of the millennium, a view of the end. Nat Genet 1999, 23:382-383

7. Nakabayashiki K, Ogino H, Michishita E, et al: Introduction of chromosome 7 suppresses telomerase with shortening of telomeres in a human mesothelial cell line. Exptl Cell Res 1999, 252:376-382

8. Lewis S, Abrahamson G, Boultwood J, Fidler C, Potter A, Wainscoat JS: Molecular characterization of the $7 q$ deletion in myeloid disorders. BrJ Haematol 1996, 93:75-80

9. Huang H, Qian C, Jenkins RB, Smith DI: Identification of YACS spanning Fra7G within the common region of $\mathrm{LOH}$ in breast and prostate cancer. Genes, Chromosomes \& Cancer 1998, 21:152159

10. Zenklusen JC, Hodges LC, LaCava M, et al: Definitive functional evidence for a tumor suppressor gene on human chromosome 7q3I.I neighboring the FRA7G site. Oncogene 2000, 19:1729-1733

II. Zang A, Zheng C, Lindvall C, et al: Frequent amplification of the telomerase reverse transcriptase gene in human tumors. Cancer Research 2000, 60:6230-6235

12. Soder Al, Hoare SF, Muir S, Going JJ, Parkinson EK, Keith WN: Amplification, increased dosage and in situ expression of the telomerase RNA gene in human cancer. Oncogene 1997, 14:10131021

13. Bryce LA, Morrison N, Hoare SF, et al: Mapping of the gene for the Human Telomerase Reverse Transcriptase, hTERT, to chromosome 5 p 15.33 by fluorescence in situ hybridization. Neoplasia 2000, 2:197-201

14. Kallioniemi A, Kallioniemi OP, Sudar D, et al: Comparative genomic hybridization for molecular cytogenetics analysis of solid tumors. Science 1992, 258:8|8-82|

15. Knuutila S, Armengol G, Bjorkqvist AM, el-Rifai W, Larramendy ML, Monni $O$, Szymanska J: Comparative genomic hybridization study on pooled DNAs from tumors of one clinical-pathological entity. Cancer Genet Cytogenet 1998, 100:25-30

16. Serakinci N, Pedersen B, Koch J: Expansion of repetitive DNA into cytogenetically visible elements. Cytogenet Cell Genet 200I, 92:182-185

\section{Pre-publication history}

The pre-publication history for this paper can be accessed here:

http://www.biomedcentral.com/1471-2350/3/11/prepub 